\title{
Online Education During Pandemic Times: Advantages and Disadvantages
}

\author{
By Daniel Moise ${ }^{1}$, Amelia Diaconu ${ }^{1}$, Mihaela Diana Oancea Negescu ${ }^{1}$, \\ Carol Cristina Gombos ${ }^{1}$
}

\begin{abstract}
The latest Pandemic has changed not only our lifestyle behavior, but at the same the manner how we work, study, and evolve. We witnessed work from home, or remote working, as well as learning from home changes. The shift from the physical classroom to the online classroom came with advantages, but also with some, disadvantages. In this article, we conducted a research to discover undergraduate and graduate students' perceptions towards online education. Students and professors are detached for the time being from their universities into online education platforms and video conference rooms, but not without other difficulties and challenges for the academic community. Some universities already had some practice and knew how to manage and use online platforms for different cycle types like: part-time or distance learning programs. Other universities appealed to platforms offered by international organizations like Microsoft or Google. The novelty was that not only the courses and seminars are held online and exams as well, proving to be a provocative issue, both for students and professors. We discovered different factors that influence online education and learning satisfaction. One of the main discoveries was that the future seems to be towards a blended learning system combining physical and online teaching.
\end{abstract}

Keywords: blended learning, online education, obstacles, online platforms

\section{Introduction}

The CoVid-19 Pandemic still affects (Nguyen et al, 2020) almost all countries in the world, and even more distressing, the medical healthcare system along with education and not only (Carra et al., 2017) (Radulescu et al., 2020). The pandemic has changed our lifestyle behavior, (Sarbu et al., 2021) the way we study, work and socializing too, in a manner never met before (Radulescu et al., 2021). If for educational system seemed (Shah et. al., 2021) easier to switch online, it was not the case for the medical system to switch to a greater extent (Pricop et al., 2016). Very few doctors appealed to consultations done via phone, using social media platforms or even video conferencing applications such as Skype, Google Meet, Zoom, Cisco WebEx, WhatsApp video, etc. (Stoica \& Burlacu, 2017) The problem was the prescription needed to be in physical form, especially if the drugs could have been bought only with a prescription as in the case of antibiotics (Faggianelli et al., 2018). In the case of education, the major concerns were regarding the primary and secondary education systems (Burlacu et al., 2021). Pupils being in the first, up to the fourth grade, and not only, encountered many hurdles in order to comprehend the lessons taught by educators (Androniceanu et al., 2017). Almost no one was ready for such an

|'Marketing Departament, Marketing Faculty, Bucharest University of Economic Studies, Bucharest, Romania. 
important swift change (Androniceanu \& Burlacu, 2017). On the other hand, some universities in higher education had (Oyedotun, 2020) some attempts to experience blended learning, especially the most well-known worldwide universities. Our university, Bucharest University of Economic Studies, known also as ASE, which is one of the top universities from Romania and South-East Europe, has also implemented blended learning before the CoVid Pandemic. ASE is the leader in some international academic rankings, like (www.ase.ro): Times Higher Education World University Ranking 2020, U-Multirank 2014 \& 2019, QS World University Rankings 2018, Times Higher Education World University Rankings 2019 being number one in the field of Social Sciences, being present in other well-known rankings. The blended learning platform that can be found at this web address https://online.ase.ro/ was used predominantly for Part-time and Distance learning education type. The final exams for each discipline took place on campus with the mandatory presence of the students. After the CoVid Pandemic started to affect the entire country and the government decided to enforce the lockdown, the courses, seminars, tutorial activities, mid-term tests and even exams were transferred online. In this paper, we deployed research to see what factors influence online education and learning satisfaction among students. Furthermore, we want to discover the advantages and disadvantages of online education from the perspective of students and master students. IA (Information Appliance) also known ICTs (Information and communications technology) - studies deployed by the scientist revealed (Jamir et al, 2019; NoirhommeFraiture et al, 2005) the fact that the exposure and use of the gadgets such as smartphones, tablets, and laptops can generate not only health problems, but also behavioral ones, and lead to social solitary and even exclusion. During the lockdown, both professors and students were obliged to be online. Despite the fact that the information can be found "at the tip of a finger", and in enormous quantities the problem is the quality of the information and how genuine and how much it reflects the truth.

\section{Review of the Scientific Literature}

Although the respiratory disease occurred (Chakraborty \& Maity, 2020) in 2019 in China, only in March 2020 WHO (World Health Organization) declared and categorized the illness as pandemic due to the ease of being transmitted from human to human. More than 1.6 billion students and master students worldwide in April 2020 started (Lenno, Reuge \& Benavides, 2021) to study from home and additionally, even student campuses were under lockdown. With the student dorms closed on the university campuses those who are from other towns, or even countries were obliged either to rent private apartments, or to go back to their families.

Digital infrastructure for eLearning platforms was not created to support such a tremendous number of users simultaneously, to transmit, upload, download, search for information and consequently encountered some issues, even in the USA and some European countries (Stoica \& Burlacu, 2017). One of the few countries that had experience in distant learning is Australia (Helmi, 2002; Bull \& Geraghty, 2019) that was prepared for it before the pandemic; both teachers and pupils had the expertise, especially those situated in rural areas. In 2017, more than 35\% of the students were enrolled (Chaku et al., 2021) in a form of distance, virtual, remote learning in comparison with 2000 when only $8 \%$ of 
the students followed this kind of study.

The transition to remote learning was realized (Aguilera-Hermida, 2020) by the use of platforms; the universities either owned the platforms or appealed to external learning platforms offered by Google and Microsoft. The transition to online education was done (Dhanalakshmi, 2021) under the pressure of time, suddenly, and in the middle of the semester. Professors and universities appealed (Hoofman. \& Secord, 2021) to asynchronous and synchronous learning.

The Pedagogical Triangle consists of the three major interactions that a student might have during the process of learning (Friesen \& Osguthorpe, 2017): Student - Teacher, Student $=$ Content and Student and Student - Student as seen in figure no 1 . The interaction (Madland \& Richards, 2016) between professor and students can increase the stimulation of interest and motivation.

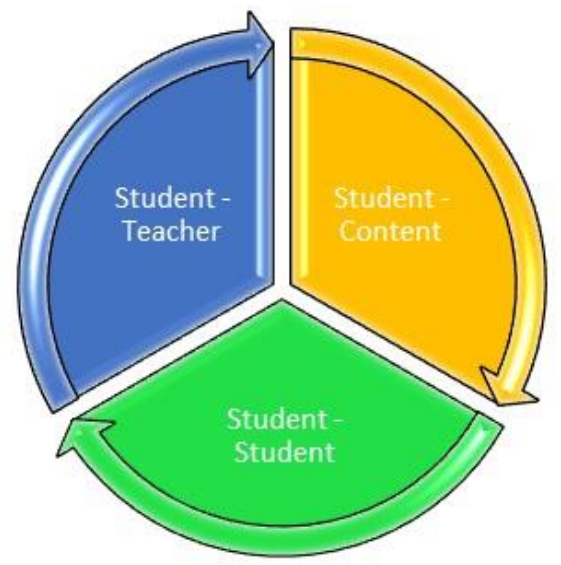

Figure no. 1. Triangle of Learning, Source: adapted after Madland, C. \& Richards G, 2016

The interaction Student - Teacher, or instructor, occurs (Friesen \& Murray, 2013) during courses and seminars. Information, homework, projects, tasks are communicated, as well as feedback can be included (Turley \& Graham, 2020) or answering the questions addressed by students during the class, or when the learners send inquiries via email, elearning platforms and through social media are sent accounts of the professor, or the tutors' phone number in order to get in touch with them (Burlacu et al., 2013).

Interaction Student - Student or learner plays a very important role especially when undergraduates and master students have to realize group projects or case studies, debates, and even collaborative brainstorming (Costache et al., 2015). It is advisable to put more emphasis, especially, during lockdowns, on this type of homework in order to be created a learning atmosphere and allow freshmen students and master students to increase socialization.

Student - Content also plays a very important role as the learner draws (Haslam, 2021) his or her conclusions and assimilates memories at the content that is given by educator, either in the form of books, power points presentations, tutorials, surveys, assignment, databases, external tools, forum, quizzes, workshops, external websites, case studies, and other educational or didactic resources. 
The factors that precede the learning tasks can be divided into two categories (Madland \& Richards, 2016):

$>$ Surface approach - students will start to resolve the tasks based on their abilities, preferences and knowledge owned.

Deep approach - the way professors designed the learning tasks that can be communicated more easily and with instant feedback while face-to-face rather than online, respecting, at the same time, the discipline objectives and the priorities of the institution.

Due to the CoVid19 pandemic, the shift was done (Aguilera-Hermida, 2020) in a very urgent and abrupt matter, taking almost everyone by surprise.

\section{Research Methodology}

Bearing in mind the problems aroused by total online education, we conducted quantitative and qualitative research with the aim to discover how the behavior of students and master students changed during the pandemic. In this article, we are going to present the findings of the qualitative research. The study was deployed starting from April 2020 - May 2021. The emphasis was also on students' perception and what improvements can be made in order that learners have a great experience and interaction with the professors. We wanted to analyze, not only the advantages, but also the disadvantages, that total online education is offering. The investigation was done among undergraduates and master students as well. The research was done using video conference platforms such as Zoom and Google Meet. At first, we had three modules student-professor interaction, studentstudent interaction, and student - content. During the research, another important point was the interaction between students - administrative staff. We appeal to in-depth interviews rather than using focus groups that are more difficult to handle especially online. One of the main issues regarding focus group research is the fact that the subjects can be influenced by the answers given by the other participants in the study.

\section{Results and Discussion}

Our depth interviews analysis was first structured in three modules, and during the study, we added, the fourth module that in our point of view can also have a degree of influence on the students' perception and experience.

The first module analyzed was a student - professor interaction. We wanted to know how the interaction is done by the tutors, if they use videoconferences platforms, education platforms, if they post the tasks for students, the number and the difficulty degree of the projects, if the projects are individual or group projects. The students and master students asked in 2020 mentioned that the platform used preponderantly by most of the professors was only the education platform, but starting with the next university year, also videoconferences platforms were used simultaneously. Some of them also mentioned the problem regarding the hacking that occurred in October, at the beginning of the first semester in 2020, making the platform unusable for a period. They mentioned that professors contacted the students and master students either by email or phone, in order to send the link for the video meetings and even the tasks, the schedule for the projects. Some of the tutors used alternative online education platforms such as google 
classroom, or even their personal or institutional email addresses where students could have sent the projects and homework. A sensitive subject was regarding if the professors obliged them during the video classes to have the video camera and the microphone turned on all the time, or only when they had to present a project, answering the questions during the courses or the seminars. We were interested not in the number of tutors obliging learners to have the camera and the microphone turned on, but more precisely how they feel about this matter. They prefer not to be obliged and brought into discussion the right to privacy and intimacy, and even GDPR issues. Some of the subjects had to go back to live with their families without having their own private room so they felt embarrassed, especially a respondent who told us about her little brother that often bothers her. They are not reluctant, when they have to present a project or case study, to turn on the microphone and the camera. They admit that when they are log on to online courses either are at work, commuting from work to home, or even making different choirs in their homes. One respondent even replied she has "a bad day and not in the mood of turning on the camera or she was not properly dressed" and she "didn't use any kind of make-up". Regarding answering, during the courses or the seminars, was problematic, without a rule or a nominalization from the professor as in the case when more of them turn on the microphone and so they can cover and interfere with the answer of another student. Students who took part in the interviews admitted that at some courses and disciplines, they developed some intellectual skills, and they seek more engaging learning materials, meaningful assignments, and to some degree, they want challenging courses. The professor should offer feedback by answering every time they have sent an email, to be replied to as soon as possible.

The second module analyzed student-student interaction. The freshmen from the first university cycle mentioned it was difficult to collaborate and to realize group projects especially those who never met their colleagues face-to-face due to the lockdown and restrictions caused by the pandemic. It was the same as in the case of the freshmen for master students, especially if they graduated from another faculty and not knowing or recognizing any of their colleagues. Students find it difficult to form groups to realize the tasks, some of them giving up and resolving group projects by themselves. A master student that went on an Erasmus scholarship mentioned that "the university where she went as student abroad, for each course and discipline for each group project they were obliged to have different team members in order that everyone invest the same time and effort in realizing the tasks". She also stated that otherwise "if students are forming the same groups for each course or discipline can follow in the trap of only one or two of the group members to realize the project, without the same amount of effort offered by all the team members". The interaction was done using social media network platforms, emails, file transfer, cloud databases, video conferences platforms, WhatsApp or Facebook Messenger and even phone calls avoiding as much possible face-to-face interaction. Most of the subjects even declared that remote or distance communication is not the same as "face-to-face", mentioning the same problems encountered as the student-professor miss communication. One of the respondents stated that he started "to work with some colleagues for a group project and for an unknown reason, two of them, out of the blue, refused to communicate, interact, answer their emails, phone calls, being forced to realize the project with fewer members". They denounce the happening to the educator, but the 
professor did not have any measure of constraints to enforce the collaboration between students. Due to these reasons, only a few of the subjects declared that they prefer individual projects rather than group projects.

The third module analyzed student-content interaction. The term "content" was explained to students meaning: books either scanned, pdf format, PowerPoint Presentations, website links for books, scientific articles, case studies documents, quizzes, and any other materials that a professor transmitted, uploaded on eLearning platforms and so on. Although more time was saved, due to the fact that students and master students did not have to commute from home or work up to the campus buildings for courses and seminars, they had more content, materials, books, tasks, case studies, homework, and even projects to deploy in comparison with coming physically. The problem that aroused was that almost at all seminars the number of tasks increased. Meeting face-to-face was easier to interact, solve case studies, problems receiving instant feedback, form minigroups of 2-3 students, and discuss during the class or finding solutions to problems by using the brainstorming method. While seminars deployed online seemed problematic and difficult to put into practice due to the limitations of the video conference platforms that are consuming also a lot of time. The complication aroused from the diminution of the interaction student with student and professor leads to the logical result of an increased number of case studies, problems, even issues to debate upon were eventually given as homework. A hypersensitive topic was the questions regarding exams, and the form of the exams, especially the online exams. Most of the subjects stated that they prefer written online exams, and the most preferred form, the quiz with multiple choices questions. The oral online exams, students perceived them as highly subjective with reference to the grades received, very tiring and time-consuming as the schedule or the programming is not always respected, being times when the examination ended after ten PM. Usually, they receive about two or three questions, and they are under stress and reluctance to answer in front of a web cam, but they do not feel at ease finding themselves in front of it.

The fourth module analyzed student-administrative staff. We have discovered that another important part of the educational experience is the interaction with the administrative staff. We can include all the personnel that is in the front office or interacts with the students. Although it was not considered, at first, as a primary or important factor, for students and master students' satisfaction regarding online education, let alone offline education, we have discovered that in many cases it can be a very important, even crucial element. The first interaction with the future students can be done either by seeing a TV ad, jingle, ad in newspapers, going to the open days, ASE representatives that come to present the University, interviews, press release, articles sponsored by ASE, etc. Another important aspect is regarding the registration process of becoming students and master students, an action which should be as easy and less stressful as possible. One of the interviewed master students even made a comparison between pre-pandemic and during pandemic registration. She was happy that the process could have been done only online without staying in long queues. Although she encountered some issues during the registration process, like not all the documents were uploaded, she was contacted also by email and phone to supply those documents in order to fully complete the process. In 2021, the communication between administrative personnel and students improved significantly in comparison with 2020 when the pandemic started. They receive replies 
more quickly regarding their problems that they encounter.

\section{Conclusions}

After compilation of the interviews, we can draw some results regarding online education and the expectation of education in general. Students and master students prefer online especially courses and seminars due to the fact they want to perform several tasks at the same time. One of the main discoveries was that the future seems to be towards a blended learning system combining physical and online teaching. Put more emphasis on group and case studies projects with at least 3 to 4 students, is mandatory for students for video interaction, synchronous debates, and discussions. The members of the group project should be different from project to project in such a way that they interact and realize the tasks with completely different colleagues.

After the study was carried out, and based on the results found, we propose a model named "The Tetragon of Education", figure no. 2, to improve the student experience during the time spent in the life cycle as a learner, and no matter if education is done online or physically. The main priority should be for the student to be in the center of attention with all the parties that he or she will interact.

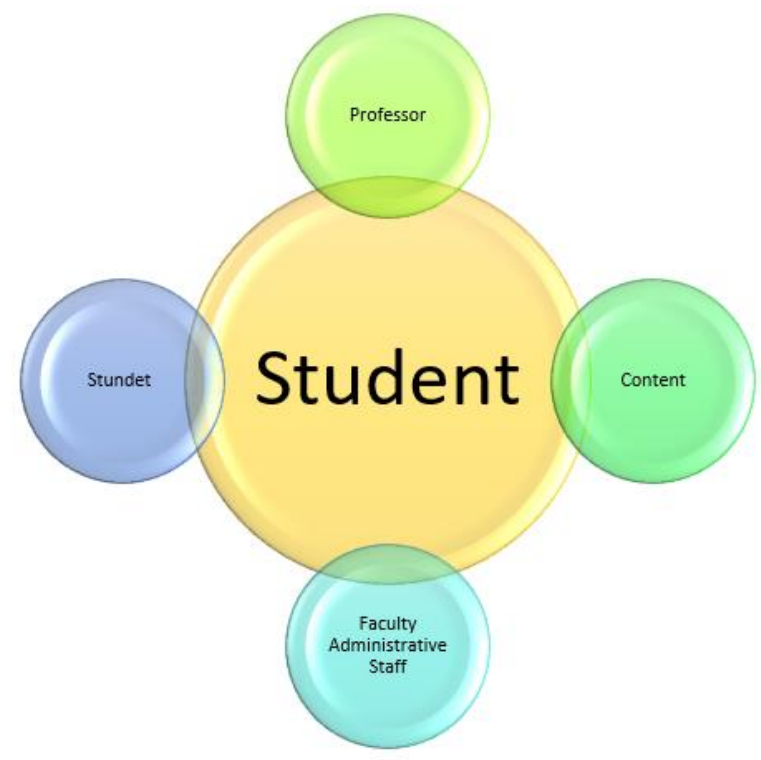

Figure no. 2. The Tetragon of Education

Regarding the limitations of the research, we also consider that the digital infrastructure and how the online educational platforms can be investigated by using quantitative research. Future research has to see if the grades have improved by having online exams versus written face-to-face exams.

The future will be blended learning, and now depends on all the parties involved to implement the good practices learned during the pandemic. 


\section{References}

Aguilera-Hermida, A. P. (2020), College students' use and acceptance of emergency online learning due to COVID-19, International Journal of Educational Research Open, Vol 1

Aguilera-Hermida, A. P. (2020),, 2020, College students' use and acceptance of emergency online learning due to COVID-19, International Journal of Educational Research Open, Vol 1

Androniceanu, A., \& Burlacu, S. (2017). Integration of educational technologies in universities and students' perception thereof. In The International Scientific Conference eLearning and Software for Education(Vol. 2, p. 26). " Carol I" National Defence University.

Androniceanu, A., Burlacu, S., Drăgulănescu, I. V., \& Nicolae, E. E. (2017, May). New trends of businesses digitalization in Romania and the behaviour young consumers. In BASIQ International Conference: New Trends in Sustainable Business and Consumption, Graz (Vol. 31, pp. 27-35).

Bull, A. \& Geraghty, S. (2019), The power of online connectivity: is the future of Australia's midwifery education a flexible online learning experience?, Journal Women and Birth, Vol 32, no 1

Burlacu, S., Enache, A. C., \& Stefan, C. (2013). INcreator-innovative software tool for creation of adaptive education digital content. In The International Scientific Conference eLearning and Software for Education (Vol. 2, p. 238). " Carol I" National Defence University.

Burlacu, S., Patarlageanu, S. R., Diaconu, A., \& Ciobanu, G. (2021). E-government in the era of globalization and the health crisis caused by the covid-19 pandemic, between standards and innovation. Les Ulis: EDP Sciences. doi:http://dx.doi.org/10.1051/shsconf/20219208004

Carra, C., Burlacu, S., \& Faggianelli, D. (2016). Violence within organizations in the health and medico-social sectors, comparative analysis France-Romania. Administratie si Management Public, (27), 123.

Carra, Cécile; Burlacu, Sorin; Faggianelli, Daniel. Violence in health organizations in Romania. The 13th Administration and Public Management International Conference. Policy And Organizational Change In Public Institutions, Oct 2017, București, Romania. 〈hal-01698150〉

Chakraborty, I. \& Maity, P. (2020), COVID-19 outbreak: Migration, effects on society, global environment and prevention, Science of The Total Environment, Vol. 728,

Chaku, N. et al., (2021), Individualized learning potential in stressful times: How to leverage intensive longitudinal data to inform online learning, Computers in Human Behavior, Vol 121,

Costache, G., Marinas, C. V., Igret, R., \& Burlacu, S. (2015). Internship in the HR Department-Organizational and Individual Perspectives. In Proceedings of the International Management Conference (Vol. 9, No. 1, pp. 359-370). Bucharest, Romania.

Dhanalakshmi, R. et. al. (2021), A study on Covid-19 - Impacting Indian education, Journal Materials-TodayProceedings

Faggianelli, D., Burlacu, S., \& Carra, C. (2018). Victimization of health professionals in Bucharest service relations and social work relationships. Administratie si Management Public, (30), 109-126.

Friesen, N. \& Murray, J., (2013), 'Open Learning 2.0’? Aligning Student, Teacher and Content for Openness in Education, Journal E-Learning and Digital Media, Vol 10, No 2

Friesen, N. \& Osguthorpe, R. (2017), Tact and the pedagogical triangle: The authenticity of teachers in relation, Journal Teaching and Teacher Education Vol 70

Haslam, B. M. (2021), What might COVID-19 have taught us about the delivery of Nurse Education, in a post-COVID-19 world?, Nurse Education Today Vol 97

Helmi, A. (2002), An analysis on the impetus of online education Curtin University of Technology, Western Australia, Internet and Higher Education no 4,

Hoofman, J. \& Secord, E. M. D., 2021, The Effect of COVID-19 on Education, Journal Pediatric Clinics of North America,

Jamir, L. et. al. (2019), Epidemiology of technology addiction among school students in rural India, Asian Journal of Psychiatry, Vol 40

Lenno, J. \& Reuge, N. \& Benavides, F. (2021), UNICEF's lessons learned from the education response to the COVID-19 crisis and reflections on the implications for education policy

Madland, C. \& Richards, G. (2016), Enhancing Student-Student Online Interaction: Exploring the Study Buddy Peer Review Activity, International Review of Research in Open and Distributed Learning, Vol 17, No 3 
Nguyen, K. D. et al. (2020), Opportunities for education during the COVID-19 pandemic, JAAD Int 2020; Vol 1, Elsevier Inc.

Noirhomme-Fraiture, M., et. al., (2005), Data Visualizations on small and very small screens, https://www.researchgate.net/publication/228872186 Data visualizations on small and very s mall screens

Oyedotun, T. D. (2020), Sudden change of pedagogy in education driven by COVID-19: Perspectives and evaluation from a developing country, Research in Globalization, Vol 2

Pricop, L. C., Burlacu, S., \& Demeter, M. L. (2016). Managing violence in health sector through bi solutions. In Proceedings of the International Management Conference (Vol. 10, No. 1, pp. 512-519). Faculty of Management, Academy of Economic Studies, Bucharest, Romania.

Rădulescu, C. V., Bran, F., Burlacu, S., Dobrea, C. R., \& Diaconu, S. (2020, December). Challenges Regarding Food Resources in the Context of Globalization and Population Growth. In Proceedings of the International Conference on Economics and Social Sciences (pp. 1041-1052). Sciendo.

Rădulescu, C. V., Burlacu, S., Bodislav, D. A., \& Bran, F. (2020). Entrepreneurial Education in the Context of the Imperative Development of Sustainable Business. European Journal of Sustainable Development, 9(4), 93-93.

Radulescu, C.V.; Ladaru, G.-R.; Burlacu, S.; Constantin, F.; Ioanăș, C.; Petre, I.L. (2021) Impact of the COVID-19 Pandemic on the Romanian Labor Market. Sustainability 2021, 13, 271. https://doi.org/10.3390/su13010271

Romero A. (2017), Online education is faulty and needs reform, https://www.researchgate.net/publication $\angle 319631391$ Online education is faulty and needs reform

Romero, A. (2016), Electronic devices bad for students in class, https://www.researchgate.net/publication $\angle 303445798$ Electronic devices bad for students in class

Sarbu, R., Alpopi, C., Burlacu, S., \& Diaconu, S. (2021). Sustainable urban development in the context of globalization and the health crisis caused by the covid-19 pandemic. Les Ulis: EDP Sciences. doi:http://dx.doi.org/10.1051/shsconf/20219201043

Shah, S. et. al. (2021), Original Online learning during the COVID-19 pandemic: Applying theselfdetermination theory in the 'new normal', Revista de Pscicodidactica

Stoica, M. M., \& Burlacu, S. (2017). Concepts and trends on e-learning in Romania. The International Journal Of Engineering And Science (IJES), 6(3), 100-105, ISSN (e): 2319 - 1813 ISSN (p): 2319 - 1805

Turley, C. \& Graham C. (2020), Interaction, Student Satisfaction, and Teacher Time Investment in Online High School Courses, Journal of Online Learning Research, Vol 5, No. 2

www.ase.ro / https://www.ase.ro/index en.asp?page=ase top accesed on 19.05.2021 